\title{
Glossary of Chinese terms
}

ban gong ban $d u$ : 'half work, half study' model

Beijing gaoshi wunian jihuashu: Beijing Higher Normal School Five-year

Plan

Beijing gaoshi guicheng: Beijing Higher Normal School Regulations

canfei jiaoyu: education for the disabled

Dao: the Way

daxue: higher education / university

dazhuan: higher education at the college level

ding dan pei yang: school-based designed training services in response to

enterprises' requests

dinggang practicum: student teaching experience programme

duikou yuanjian: policy to strengthen co-operation and support

between inland developed provinces and less developed western

minority regions

duli sikao: independent thinking

gaodengjiaoyu: higher education

gaokao: National Higher Education Entrance Examination

gongjian: joint jurisdiction

gong jian sheng: admission priority based on company donation

gong xue jie he: combining learning with working

gongtongti: communities

guanxi: social capital producing social connections and influence

guimao xuezhi: educational system promulgated by the Qing dynasty

in 1904

hebing: merger

hezuo: cooperation

ji gong xue xiao: skilled worker schools

jiji fabiao jianjie: actively express opinions

jiao xue gong chang: vocational training school

jinqu jingshen: eagerness to make progress

jueding: choosing and decision making

K'ang-ta: Anti-Japanese Military and Political College

ke cheng zhi huan: retraining courses developed by training service

companies

kecheng: programme/major

keju: imperial civil examination 
liang mian: 'two exemptions' (from payment for tuition and books) meng yang yuan: early childhood education programme before 1920 min kao han: ethnic minority individuals receiving mainstream education min kao min: ethnic minority individuals receiving bilingual education minzu: ethnic minority minzu daxue: university for ethnic minorities minzuban: classes for ethnic minority students minzu xueyuan: institute for ethnic minorities neidi: inland neidi minzu ban: classes for ethnic minority students in inland cities neidi Xinjiang ban: inland Xinjiang classes neidi Xizang ban: inland Tibet classes neidiban: Guidelines on East-West Schools Partnership and Support

Building programme Ping Min Jiao Yu: Mass Education Movement Pinyin: romanized standard Chinese putong zhong xuetang: regular middle schools Putonghua: standard spoken Chinese, based on the Beijing dialect quannaxing jiaoyu: inclusion renхи хиеzhi: the educational system introduced by the Beiyang government in 1922 renyin xuezhi: the educational system introduced by the Qing dynasty in 1902 renzi guichou: the new educational legislation introduced by Republican

China in 1912 sanbao: Three Guarantee Policy shaoshu minzu gao cengci gugan rencai jihua: the high-level ethnic minority talents plan shifan: 'the teacher as a model' / 'normal' shifan guan: institute for the cultivation of teachers in modern society Shiji Jiaoyu Diaochashe: Society for Practising Educational Research shiye xuetang: vocational schools shuyuan: a type of school in ancient China suiban jiudu: learning in the regular classroom suzhi jiaoyu: quality education for all-round development teshu jiaoyu: special education $t i$ : essence tianren heyi: traditional Chinese view that humanity is an integral part of nature tiaozheng: adjustment or transfer of jurisdiction tuo er suo: nursery school wenhua anquan: cultural integrity 
xiao qi he zuo: school-enterprise cooperation

xiaoxuetang: elementary schools in modern China

xuanze: choice

xue qian ban: pre-primary school class

xuexiao: institition

yang wu yun dong: Westernization movement

yitihua jiaoyu: integration

yong: usefulness

you er yuan: kindergarten

you zhi yuan: early childhood education programme after 1922

yuanxi: institution

zao jiao zhong xin: early childhood education centre

zhenzheng jieshou: accept genuinely

zhi jiao ji tuan: vocational education group

zhi ye da xue: vocational universities

zhi ye gao zhong: vocational high schools

zhi ye ji shu xue yuan: vocational and technical college

zhongdengxuetang: middle schools in modern China

zhong deng zhi ye ji shu xue xiao: secondary vocational and technical school

zhong deng zhuan ye xue xiao: secondary specialized schools

zhongguoxuesheng: Chinese student

zhongkao: senior secondary

zhongti xiyong: learning science and technology from Western countries

while developing Chinese Confucian morality and culture

zhuan ke xue xiao: further education colleges in 1950s as supplement to secondary vocational education

zhuanmen xuetang: specialized colleges

zhuanxiang jingfei: special project subsidy

zhuanye: programme/major

ziyou biaoda: express openly 